\title{
Cerebral infarction due to carotid occlusion and carbon monoxide exposure. I. Pathophysiological and neuropathological investigations
}

\author{
RUDOLF LAAS, JÖRG IGLOFFSTEIN, SOLVEIGH MEYERHOFF
}

From the Department of Neuropathology, Eppendorf Hospitals, University of Hamburg, Hamburg, Federal Republic of Germany

SUMMARY Ligation of one common carotid artery and exposure to carbon monoxide has proved to be a reliable method of producing unilateral cerebral infarcts in the rat, allowing controlled experiments in any given sample size. Pathophysiological measurements in awake and narcotised rats has shown that, in contrast to hypoxic hypoxia, the carbon monoxide-induced functional anaemia (3000 ppm in room air) did not stimulate chemoreceptors, thus causing a severe systemic hypotension owing to peripheral vascular dilatation. This hypotension is likely to represent the main pathogenetic factor in this model. An inhibition of ferro-enzymes by carbon monoxide did not seem to be involved. The only cause of death was shown to be diffuse ipsilateral brain oedema with or without extra-vasation of serum proteins. The EEG, the systemic arterial pressure, rotational behaviour, and carotidal stump pressure proved to be reliable predictors of outcome.

Small animal models are valuable in the investigation of brain infarction by providing a sample size sufficient for statistical analysis. Those models producing unilateral infarcts are further advantageous in that the contralateral hemisphere is available for comparison in morphological and biochemical investigations. Moreover, unilateral infarcts allow the study of brain damage by way of lateralised neurological signs.

The mongolian gerbil is useful for the development of unilateral brain infarcts after ligation of one common carotid artery owing to functional insufficiency of the circle of Willis. ${ }^{1}$ However, this animal is not large enough for easy invasive monitoring of its effects. This objection does not hold for the Levine model in which unilateral brain infarcts are produced in the rat by ligation of one common carotid artery and subsequent exposure to hypoxic hypoxia. $^{2}$ However, the hypoxia induces a sympatho-adrenal stimulation so that substantial oxygen deficiency is required for cerebral infarcts to result, and this demands close monitoring of the

Address for reprint requests: Rudolf Laas, MD, Department of Neuropathology, Eppendorf Hospitals, University of Hamburg, Martinistrasse 52, 2000 Hamburg 20, Fed Rep Germany.

Received 6 August 1982 and in revised form 18 January 1983. Accepted 4 March 1983 individual animal. ${ }^{34}$ This difficulty can only be overcome by controlling hypoxaemia and arterial blood pressure by means of continuous anaesthesia and artificial respiration. ${ }^{5}$ We therefore attempted to avoid stimulation of the chemoreceptors by using a functional anaemia induced by carbon monoxide. This procedure proved to be reliable and amenable to controlled experiments.

\section{Material and methods}

Male albino rats (Chbb:THOM strain) had free access to standard rat chow and tap water.

Series I

After anaesthesia with diethyl-ether one common carotid artery was ligated and transsected. Twenty-four hours later the animals were exposed to carbon monoxide (3000 ppm in room air) for 90 minutes while held in a plastic box with a volume of $300 \mathrm{l}$, allowing the exposure of eight animals at a time. The gas mixture was stirred by a fan. The concentration of carbon monoxide was continuously monitored inside the plastic container and in its immediate vicinity by an infrared spectrometer (URAS I, Hartmann \& Braun, FRG) to assure a continuous exposure of the animals and to protect laboratory personnel against accidental leaks. At the 48th hour after exposure the rats were anaesthetised with diethyl-ether and perfused via the ascending aorta with formalin after briefly washing out the vasculature with saline. 


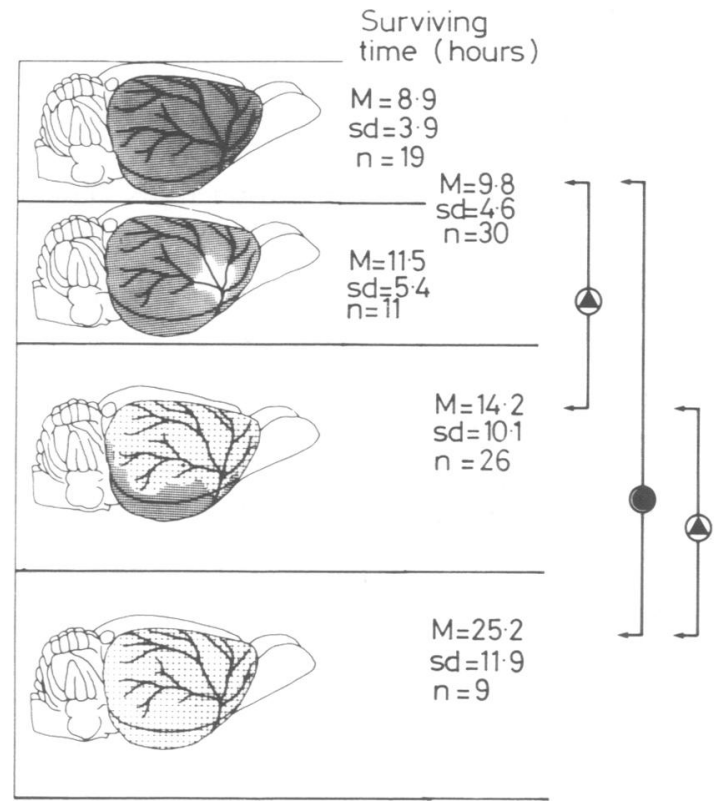

Histological evaluation of the brains was performed in two frontal planes which were found to be representative of the extent of the infarct. One plane was through the medial portion of the anterior commissure and the other through the greatest extent of the thalamus.

Brain damage was graded as follows: 0/I: no lesion or small, patchy necrosis, II: subcortical-damage, with the cortex involved to less than one half of its total extent, III: damage of greater extent than II.

For the purpose of statistical analysis we recorded the regional incidence of brain lesions in each sample by counting how often the fields of a standardised grid were covered to more than $50 \%$ by the lesion (fig 4).

Blood-brain barrier. All animals received an intraperitoneal injection of Evans blue $(1 \mathrm{ml}, 1 \%$ solution in saline) at 2 to 4 hours before carbon monoxide exposure. Extravasation of the tracer was determined by gross inspection and fluorescence microscopy. In order to determine the point of time at which blood-brain barrier breakdown occurred eight animals each were decapitated $30,45,90$ and 210 minutes after carbon monoxide exposure.

Body temperature, respiratory rate. In all animals rectal temperature was measured by a thermal probe before and after carbon monoxide exposure. The respiratory rate was registered several times during and after carbon monoxide exposure.

Carboxyhaemoglobin concentration. In a total of 74 animals the concentration of carboxyhaemoglobin $(\mathrm{CO}-\mathrm{Hb})$ was determined spectrometrically in mixed blood nine, 15 and 90 minutes after start of the carbon monoxide exposure and five, 30, 60, 90 and 120 minutes after its cessation.

Rotational behaviour. In 107 animals the behaviour was monitored by video-tape. Rotational behaviour consists in narrow circling movements with the outer forelimbs being extremely splayed. For every five minutes the number of rotating animals and the mean number of rotations in these animals were determined.

\section{Series II}

Common carotid artery stump pressure. In 22 anaesthetised rats the mean arterial blood pressure was monitored distally and proximally to the common carotid artery ligation by means of PVC catheters. Twenty-four hours later these animals were exposed to carbon monoxide for 90 minutes as described above (series I).

\section{Series III}

Flow direction in the carotid arteries. Twenty anaesthetised animals (ketamine) underwent ligation of one common carotid artery. Boli of Evans blue were injected into the contralateral common carotid artery to visualise the flow direction in the ipsilateral carotid bifurcation and in the pterygopalatinal artery. In three animals the flow of the dye boli was observed 24 hours after common carotid artery ligation.

\section{Series IV}

Arterial blood gases and pH. In 14 lightly anaesthetised animals (ketamine) the mean arterial blood pressure was monitored via a catheter inserted into the proximal stump of the ligated common carotid artery during the carbon monoxide exposure and for 90 minutes thereafter. Simultaneously, the unipolar biparietal EEG (for technical details see series $V$ ) and the rectal temperature were registered. The $\mathrm{CO}-\mathrm{Hb}$ concentration, the arterial pO2, pCO2, and $\mathrm{pH}$ were determined (IL-Boskamp, FRG) in intermittant arterial blood samples of $100 \mu \mathrm{l}$. The carbon monox- 
ide exposure had to be restricted to 35 minutes, owing to the limitations of anaesthesia.

\section{Series $V$}

Measurements in unanaesthetised animals. In 18 animals unanaesthetised and unrestrained, the mean arterial blood pressure, the heart rate, the respiratory rate and unipolar biparietal EEG were continuously monitored before, during and for $\mathbf{8 0}$ minutes after a carbon monoxide exposure of 70 minutes duration.

Seven days before carbon monoxide exposure two silver electrodes were implanted epidurally into the parietal calvaria and one into the os nasale; the electrodes were fixed onto the skull by means of screws and plastic. Eight hours before the carbon monoxide exposure a silastic tube was inserted into the proximal stump of the ligated common carotid artery, fixed and installed subcutaneously up to the plastic mount on the skull. Two hours before carbon monoxide exposure a small pressure transducer (P37, Statham, USA) was connected to the tube. For carbon monoxide exposure the animals were held in a gas tight plastic tube $(50 \mathrm{~cm}$ in diameter, $100 \mathrm{~cm}$ in height). The wires from the electrodes and the transducer were connected to the amplifiers via a slip ring assembly (BRS, USA). The carbon monoxide concentration inside the tube (3000 ppm in room air) and in its immediate vicinity was continuously monitored by means of an infrared spectrometer. Eighty minutes after the carbon monoxide exposure the wires of the electrodes and of the transducer were disconnected and the animals were further observed for six to seven hours. The EEG was evaluated visually. For statistical analysis the lowest EEG frequency and the corresponding amplitude were considered.

All numerical data were statistically analysed by Fisher's exact probability test, Chi-square test and Student's $t$ test for nonparametric and parametric data respectively.

\section{Results}

\section{SERIES I}

The occlusion of one common carotid artery did not cause any detectable neurological or behavioural symptoms.

Lethality. During the carbon monoxide exposure $8 \%$ of the animals died. After cessation of the carbon monoxide exposure $20 \%$ of the animals died within two to 48 hours (figs 1,2 ).

Histological findings. In a representative sample of 86 animals the distribution of the histologically determined infarcts on our scale was as follows: 0/I: 23 (27\%); II: 37 (43\%); III: 26 (30\%).

The infarcts were typically located along the rhinal fissure (fig 3). The laterobasal cortex, the hippocampal cortex, the striatum and the amygdala were mostly involved. The intensity of the lesions ranged from neuronal to total necrosis. From a total of 38 animals which had died during the carbon monoxide exposure, 23 had no cerebral alteration, 12 showed a slight pallor of the ipsilateral hemisphere and three showed a distinctly demarcated pallor of the typical zone of infarction. In no case could brain swelling be detected. All animals which died after cessation of the carbon monoxide exposure had massive ipsilateral brain swelling with considerable softening of the tissue and herniation.

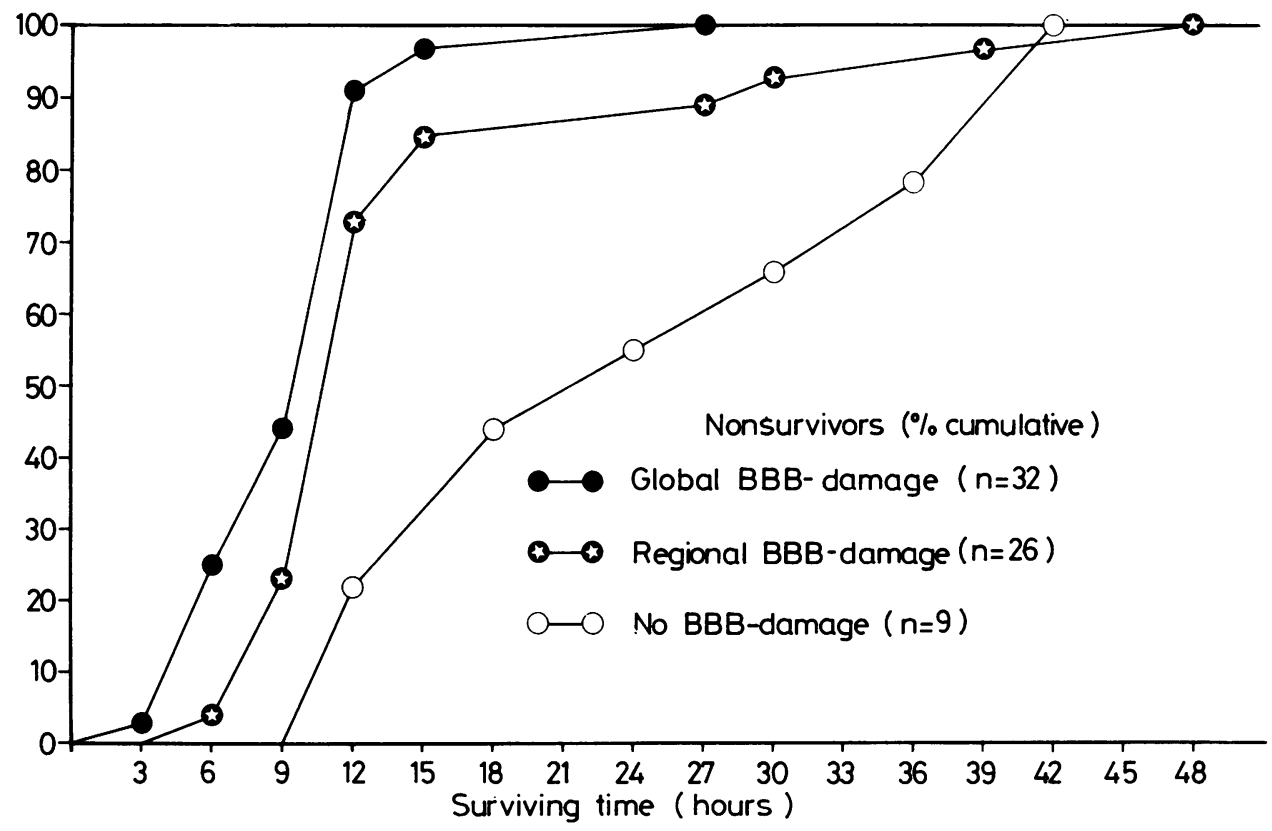

Fig 2 Cumulative distribution of the survival time in nonsurvivors with global, regional or no blood-brain barrier (BBB) damage, respectively. 

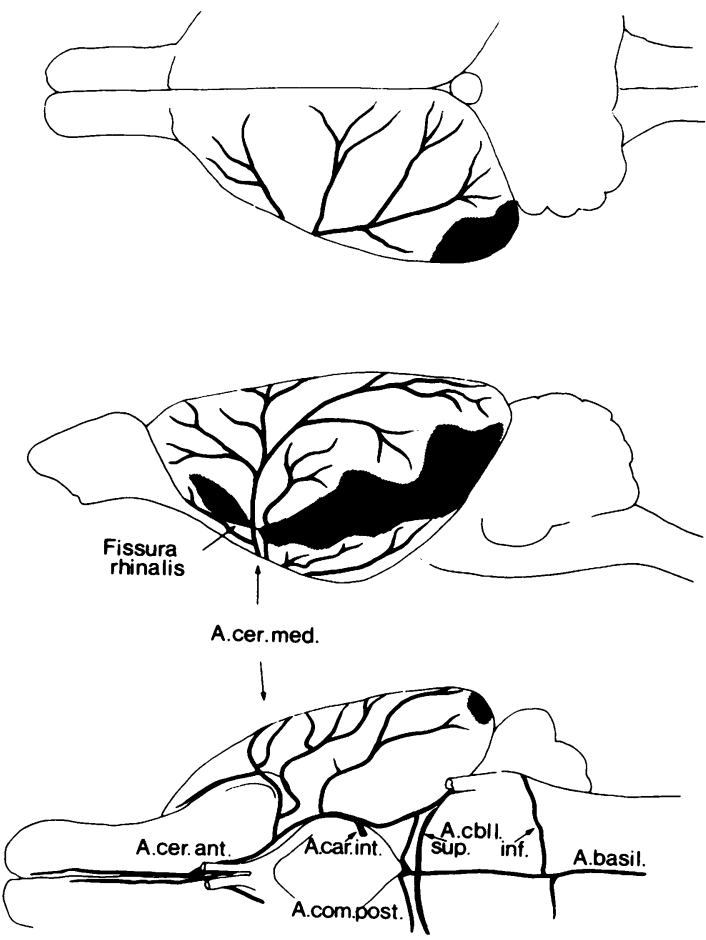

Fig 3 The leptomeningeal arteries of the rat and the typical localisation of the infarcts.

Blood-brain barrier. An extravasation of Evans blue was regularly found in the zones of completed infarction. The concentration of Evans blue was most marked in the perikarya of the neurons. In 65 animals which had died after cessation of the carbon monoxide exposure three different patterns of blood-brain barrier damage could be detected. In 30 animals diffuse blood-brain barrier damage developed in the region of the ipsilateral brain oedema. In 26 animals extravasation of Evans blue was restricted to the zone of regional infarction, whereas the remaining hemisphere showed only marked swelling and pallor. In nine animals there was a massive ipsilateral brain swelling without Evans blue extravasation. The mean survival time increased in the given order of patterns (figs 1,2).

In none of the animals which had died during the carbon monoxide exposure could extravasation of Evans blue be detected. This was so too for the eight animals which were decapitated 30 minutes after cessation of the carbon monoxide exposure. Four of them presented a distinct pallor in the typical zones of infarction and three showed a slight pallor of the ipsilateral hemisphere. Evans blue extravasation was seen at the earliest 45 minutes after termination of the carbon monoxide exposure. In 11 of the 24 animals which were decapitated 45, 90 and 120 minutes after cessation of the carbon monoxide exposure the typical zones of infarction were distinctly demarcated by an oedematous zone. Within these regions a blue tinge was detected.

Body temperature, respiratory rate. During the carbon monoxide exposure the rectal temperature fell from $38.8^{\circ} \mathrm{C}$ to $32 \cdot 1^{\circ} \mathrm{C}$. The respiratory rate became maximum at 30 minutes and then remained unchanged until termination of the carbon monoxide exposure. Neither rectal temperature nor respiratory rate correlated with chances of survival. Carboxyhaemoglobin concentration reached a plateau of $55 \%$ at the end of the first 20 minutes of the carbon monoxide exposure. It decreased much more slowly after the cessation of the exposure (fig 5).

Rotational behaviour. The number of rotating animals reached an initial peak between the 10 th and 15th minute of the carbon monoxide exposure. It diminished between the 20th and 25 th minute and
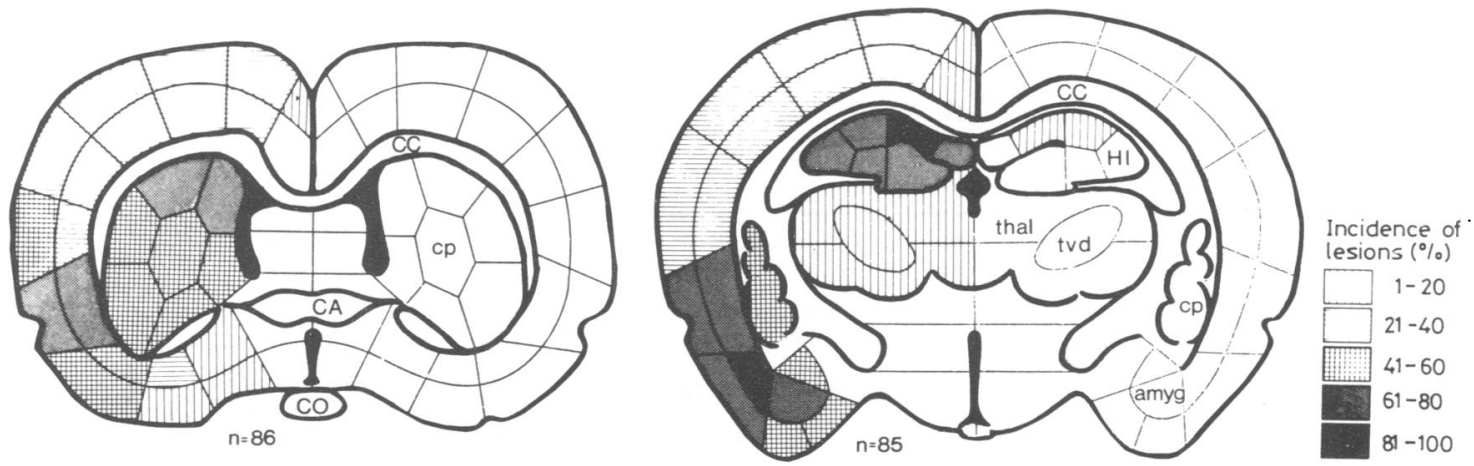

Fig 4 Pattern of infarct distribution projected onto the standardised grid in the two standard frontal planes. CC: corpus callosum; CA: anterior commissure; CO: optic chiasm; cp: caudatum-putamen; HI: hippocampus; thal: thalamus; tvd: nucleus ventralis thalami, pars dorsomedialis. 


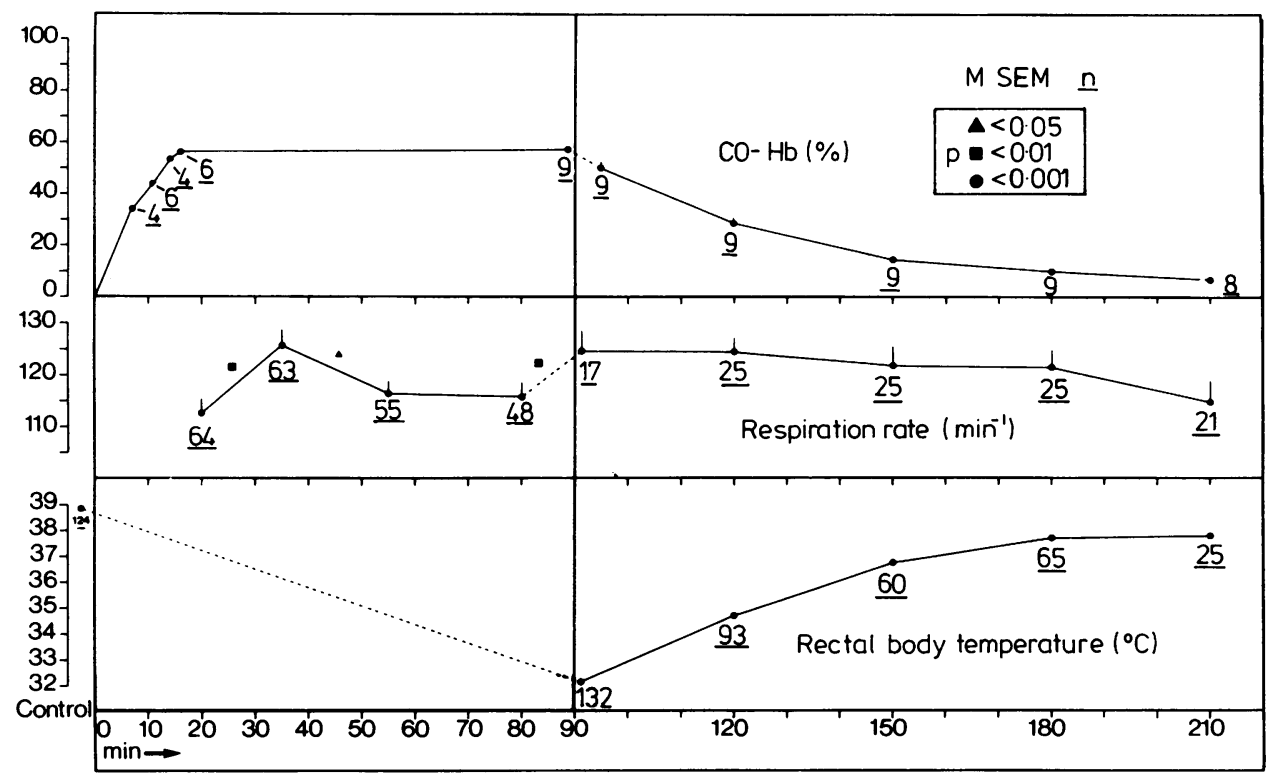

Fig 5 Changes in $\mathrm{CO}-\mathrm{Hb}$ concentration, respiratory rate and rectal body temperature before, during and following a carbon monoxide exposure in rats which had undergone unilateral common carotid artery ligation.

remained constant from the 40th minute until termination of the exposure (fig 6).

During the initial peak contraversive rotation predominated $(41 \%$ vs. $7 \%)$, whereas during the plateau phase ipsiversive rotation prevailed $(33 \%$ vs. $20 \%$ ). The proportion of rotating animals showed a slight maximum between the 30th and 40th minute (fig 6). In animals with slight or no brain injury contraversive rotation predominated during the initial phase (60\% vs. $9 \%$ ) and during the plateau phase $(50 \%$ vs. $15 \%$ ) (fig 7$)$. In animals with moderate or severe lesions, contraversive rota- tion predominated also during the initial phase (40\% vs. $8 \%$ ). During the plateau phase, however, ipsiversive rotation prevailed $(30 \%$ vs. $10 \%)$. Amongst nonsurviving animals a gradual decline of the number of rotating animals occurred during the carbon monoxide exposure (fig 7). During the plateau phase these animals behaved like the moderately or severely affected surviving ones $(20 \%$ ipsiversively rotating rats vs $4 \%$ contraversively rotating ones), and it was not until the recovery phase that the behaviour of the survivors differed distinctly from that of the nonsurvivors. In the

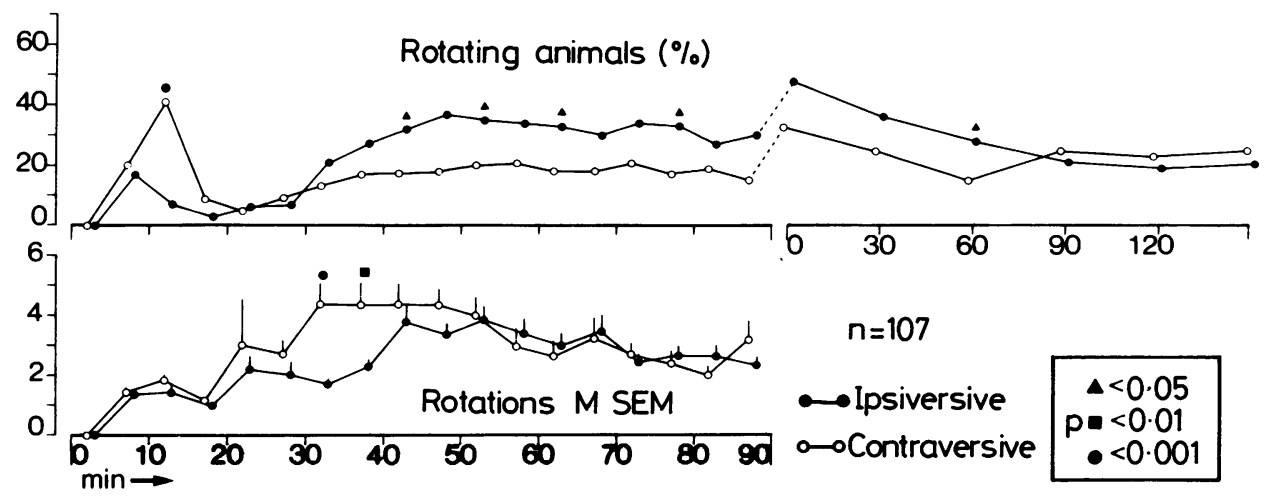

Fig 6 Changes in the rate of ipsi- and contraversive rotation during and following a carbon monoxide exposure (top). Changes in the mean rate of rotations (per five minutes) (bottom). 


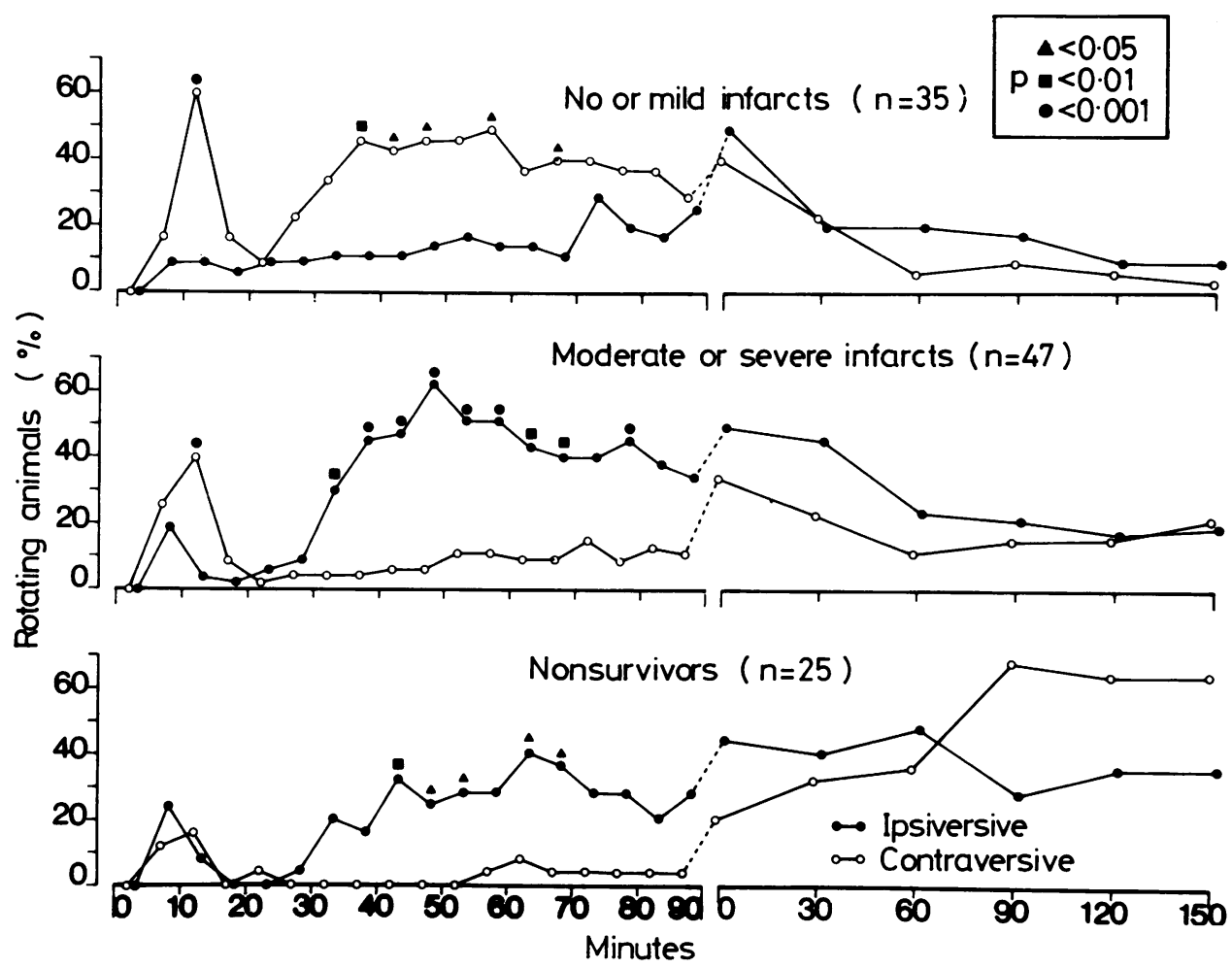

Fig 7 Changes in the number of rats exhibiting ipsi-and contraversive rotation and developing no or mild infarcts (top), moderate or severe infarcts (middle) and of nonsurvivors (bottom) during and following a carbon monoxide exposure.

recovery phase the number of rotating animals in the survivors decreased steadily and in the nonsurvivors it increased gradually. Contraversively rotating animals predominated (fig 7).

\section{SERIES II}

Common carotid artery stump pressure. The distal arterial blood pressure ranged within $35 \%$ and $55 \%$ of the systemic arterial blood pressure. Following the carbon monoxide exposure, six out of 11 animals with a distal arterial blood pressure of less than $45 \%$ of the systemic arterial pressure developed moderate to severe brain lesions. In the remaining 11 animals with a distal stump pressure of more than $45 \%$ of the systemic arterial pressure no brain lesions were detected $(p<0.02)$.

\section{SERIES III}

Flow direction in the carotid arteries. The contralaterally injected bolus of Evans blue passed through the ipsilateral internal carotid artery into the external carotid in all 17 animals. The same flow direction was observed when tested 24 hours after common carotid artery ligation. In four rats the bolus entered the circle of Willis and the pterygopalatinal artery nearly simultaneously. In four others the boli passed retrogradely through the pterygopalatinal artery. One part passed towards the circle of Willis and the other part passed retrogradely towards the carotid bifurcation.

\section{SERIES IV}

Arterial blood gases and $p H$. In the 14 ketamine anaesthetised animals mean arterial blood pressure had already fallen to $55 \mathrm{~mm} \mathrm{Hg}$ after 20 minutes and to $46 \mathrm{~mm} \mathrm{Hg}$ at the end of the carbon monoxide exposure. $\mathrm{CO}-\mathrm{Hb}$ concentration reached a maximum of $65 \%$, The arterial $\mathrm{pO}_{2}$ decreased from a control level of $88 \mathrm{~mm} \mathrm{Hg}$ to $78 \mathrm{~mm} \mathrm{Hg}$ at the 20th minute of the exposure and then increased again to $85 \mathrm{~mm} \mathrm{Hg}$ at the end of the exposure. There was a slight hypocapnia and acidosis at the end of the exposure with the $\mathrm{pH}$ reaching its minimum at the 10 th minute of the recovery phase (fig 8). 


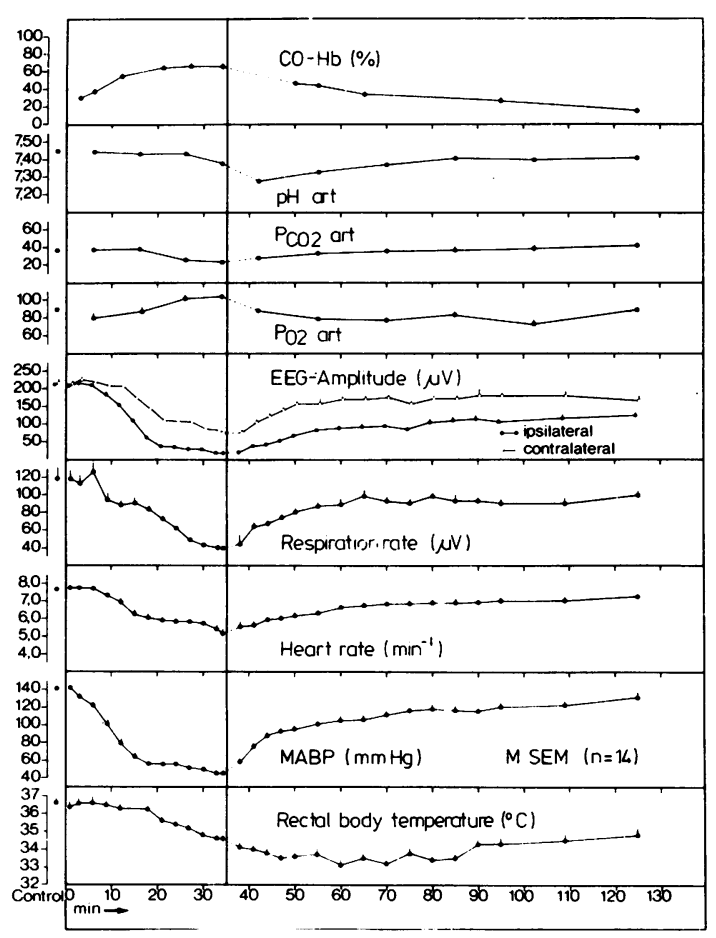

Fig 8 Changes in $\mathrm{CO}-\mathrm{Hb}$ concentration, mean arterial blood pressure (MABP), heart rate, EEG, respiratory rate, rectal body temperature and arterial $\mathrm{pH}, \mathrm{pCO}_{2}$, and $\mathrm{pO}_{2}$ during and following carbon monoxide exposure of 35 minutes duration in 14 slightly anaesthetised animals.

\section{SERIES V}

In the awake unrestrained animals there was a slight tachycardia by the 10th minute of the carbon monoxide exposure which was followed after only one to two minutes by a fall of the mean arterial blood pressure from a base level of $113 \mathrm{~mm} \mathrm{Hg}$ to a minimum of $77 \mathrm{~mm} \mathrm{Hg}$ by the 12 th minute.

After 10 minutes of the carbon monoxide exposure the EEG frequency decreased and the EEG amplitude increased bilaterally. Ipsilaterally this was followed by a synchronous and abrupt decrease of frequency and amplitude, reaching the zero line by the 20th minute. Contralaterally the depression was at maximum by the 25 th minute of the carbon monoxide exposure. Later on, a gradual restitution took place until termination of the exposure.

The respiratory rate varied greatly between individuals. During the second half of the carbon monoxide exposure in 14 of the 18 animals episodes of bradycardia occurred. They were of 10 to $20 \mathrm{sec}-$ onds duration with intervals of 20 to 30 seconds. They disappeared within 60 to 120 seconds after cessation of the carbon monoxide exposure. Elec- trocardiographic studies showed that this bradycardia was due to heart block with an artrioventricular ratio of 2:1 (unpublished data).

Nine of the 18 animals died within 12 hours after the carbon monoxide exposure and showed severe ipsilateral brain swelling. During the carbon monoxide exposure the course of the physiological variables found in the nonsurvivors did not differ from that detected in the survivors (fig 10). However, after the carbon monoxide exposure recovery of the ipsilateral EEG was, by comparison, delayed in the nonsurvivors. From the 20th minute of the recovery phase onwards, the increase of the mean arterial blood pressure was steeper in the nonsurvivors than in the survivors.

\section{Discussion}

According to the binding characteristics of $\mathrm{CO}-\mathrm{Hb},{ }^{6}$ very low concentrations of carbon monoxide reduce considerably oxygen availability in the tissues. The arterial oxygen pressure measured during the carbon monoxide exposure did not fall short of the threshold below which the chemoreceptors are stimulated, which is within the range 70 to $80 \mathrm{~mm}$ Hg. ${ }^{7}$ Since the chemoreceptors have been found to be insensitive to partial carbon monoxide pressure, $\mathrm{CO}-\mathrm{Hb}$ concentration and oxygen content, ${ }^{78}$ chemoreceptor-induced circulatory responses were absent in our animals. They consist of elevation of respiratory rate and tide, increase of systemic arterial blood pressure and cardial output and in tachycardia..$^{9-12}$ There is also an activation of the hypothalamo-hypophyseo-adrenocortical system. ${ }^{13}$ After denervation of the carotid and aortal chemoreceptors the circulatory and respiratory reactions induced by hypoxic hypoxia no longer differ from those induced by carbon monoxide. ${ }^{12} 1415$

The drop of systemic arterial pressure starting two minutes after the beginning of the carbon monoxide exposure confirms observations made in rats, ${ }^{16-18}$ rabbits, ${ }^{14}{ }^{15}$ guinea pigs, ${ }^{18}$ dogs, ${ }^{12} 1920$ and monkeys. ${ }^{21}$ The steepness of the pressure fall seems to depend on the rate of increase of the $\mathrm{CO}-\mathrm{Hb}$ concentration. ${ }^{161719}$ Investigations in rabbits ${ }^{141522}$ and dogs ${ }^{12}$ show that lowering of the systemic arterial pressure results mainly from a decrease of the total systemic peripheral vascular resistance induced by the anaemic hypoxia. In contrast to what is observed in monkeys exposed to severe hypoxia, ${ }^{23}$ it appears not to depend on cardiac dysfunction. ${ }^{24}$ The initial tachycardia (fig 9) probably is mediated by baroreceptor afferents. ${ }^{13} 15$ It was diminished or absent in anaesthetised animals. ${ }^{181921}$

During the period of cardiorespiratory stabilisation which could be recognised from the 25 th to 


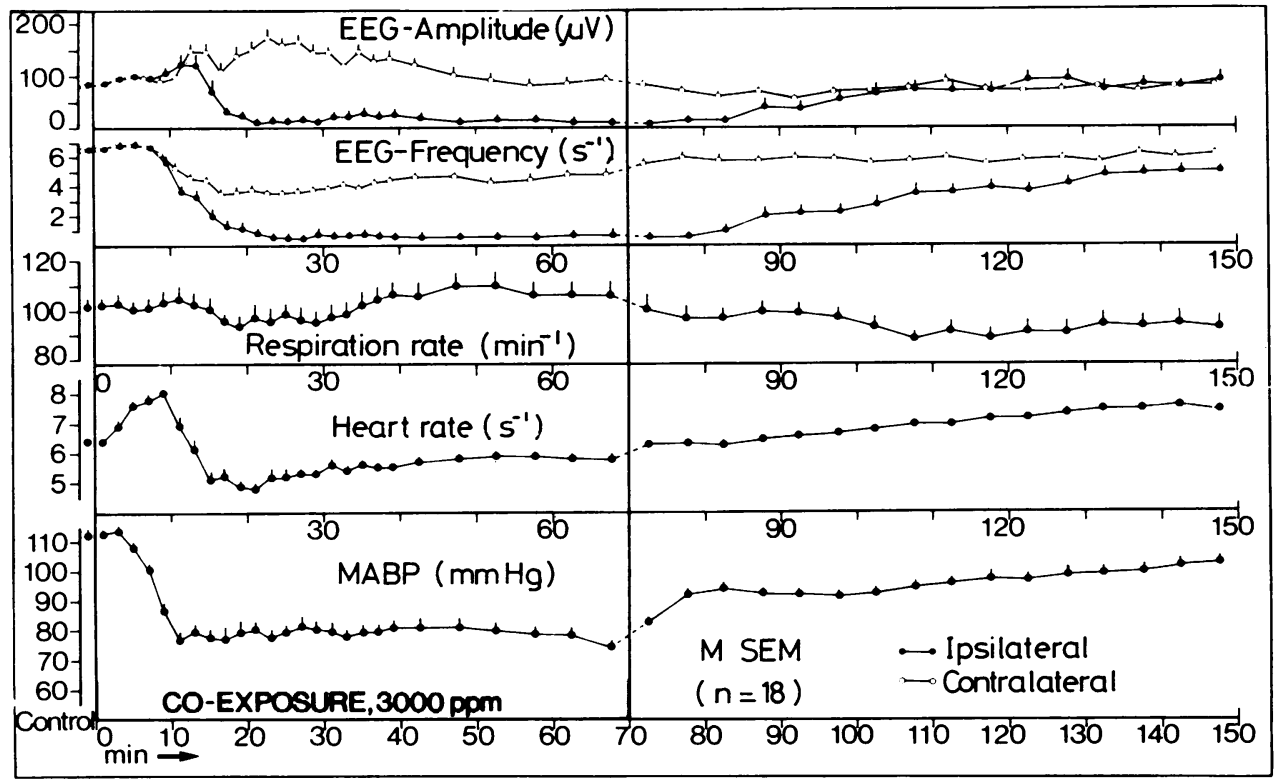

Fig 9 Changes in mean arterial blood pressure (MABP), heart rate, respiratory rate and in the predominant EEG frequency and amplitude before, during and following carbon monoxide exposure of 70 minutes duration.

30th minute of carbon monoxide exposure onwards a central arousal reaction occurred as shown by an increase in the frequency of the contralateral EEG and a decrease of the EEG amplitude as well as by a marked increase of the respiratory rate and of the number of rotating animals (fig 6). The conspicuously prompt disappearance of the cardiac block within one to two minutes after termination of the carbon monoxide exposure agrees with observations made in monkeys. ${ }^{21}$ This phenomenon probably can be attributed to direct myocardial reactions to the pCO. 2526

In our experiments the infarct incidence increased when the pressure distal to the common carotid artery ligation fell below about $45 \%$ of the systemic arterial blood pressure, that is below $35 \mathrm{~mm} \mathrm{Hg}$ during the carbon monoxide induced hypotension of about $80 \mathrm{~mm} \mathrm{Hg}$ (figs $8,9,10$ ). Since the bolus experiments (series II) revealed that - at least with normotension-there was consistently a pressure difference between the external and internal carotid arteries in favour of the latter, it is probable that the effective blood pressure within the ipsilateral semicircle of Willis exceeded the distal arterial stump pressure also during hypotension. The threshold of arterial blood pressure for the development of regional brain infarct has been assessed in cats $^{27}$ and monkeys ${ }^{28}$ to be about $25 \mathrm{~mm} \mathrm{Hg}$, provided the duration of the hypotension exceeds 20 or 30 minutes respectively. Within a systemic arterial pressure range of 15 to $25 \mathrm{~mm} \mathrm{Hg}$ the amplitude of the primary evoked response became zero in the cat. ${ }^{29}$ In the Monogolian gerbil we found the threshold value of ipsilateral carodtidal stump pressure for regional infarction to be of a similar magnitude when the duration of the common carotid artery ligation was unlimited..$^{30}$ Data concerning critical arterial pressure threshold values and the respective time needed for the production of brain infarcts in the rat are not yet available. However, by analogy, during the carbon monoxide exposure the distal arterial blood pressure of the animals destined for infarction appeared to exceed the infarct threshold value by about $10 \mathrm{~mm} \mathrm{Hg}$. From this it can be inferred that the anaemic component plays an important part in the pathogenesis of the infarcts. Our model should therefore be classed with anoxicl anaemic-ischaemic models. This accords with the quite consistent vulnerability of our animals (figs 1 , 3,4 ) which was similar to that found in the Levine model. ${ }^{2331}$ This infarction seems not to depend on whether the hypoxic-anaemic or the ischaemic component preponderates, since it has also been shown to result from severe hypoxaemia with only slight hypotension produced by common carotid artery ligation, the systemic arterial blood pressure being maintained at a normal level. ${ }^{32}$

In contrast to what is observed in the Levine pre- 


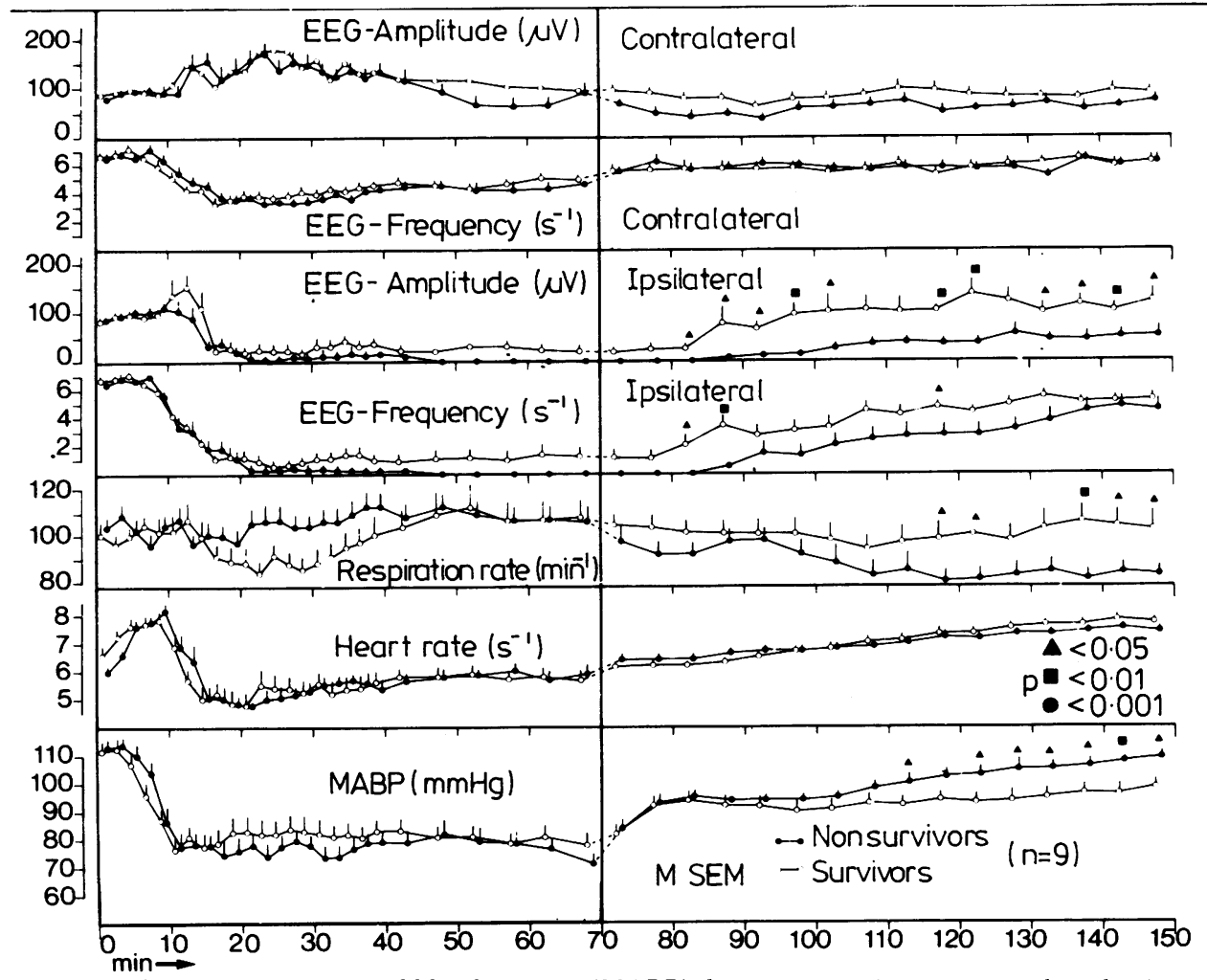

Fig 10 Changes in mean arterial blood pressure (MABP), heart rate, respiratory rate and predominant EEG frequency and amplitude during and following carbon monoxide exposure of 70 minutes duration. Comparison between surviving $(n=9)$ and nonsurviving $(n=9)$ rats.

paration $^{31}$ we never saw focal brain lesions in the contralateral hemisphere. This suggests that the hypoxic component plays a more important role in the Levine preparation than the anaemic one in our model. The pallor of the infarcted brain in animals which died during the carbon monoxide exposure or which were sacrificed within 30 minutes thereafter indicates that there was cytotoxic brain oedemia. This is well known to occur early in the development of regional ischaemic brain infarcts ${ }^{33} 34$ and of anoxic-ischaemic brain lesions. ${ }^{3{ }^{31}}$ The later occurrence of Evans blue extravasation agrees with observations of others. ${ }^{333337}$ It demonstrates that the areas which subsequently become necrotic are regularly reperfused after cessation of the carbon monoxide exposure. The capillaries appeared not to be occluded completely by the cytotoxic brain oedema or by other mechanisms which might impede recirculation within the infarcted area as, for example, aggregation of platelets, sludging of erythrocytes; intraluminal membrane bound bodies and arterial spasms. ${ }^{33} 3637$

Since the nonsurvivors showing brain swelling without extravasation of albumin-dye complexes exhibited the longest survival time, the failure to demonstrate Evans blue extravasation is not likely to be simply due to an arrest of brain perfusion. This requires further investigations. There is evidence that the development of ischaemic brain lesions is not dépendent on damage of the blood-brain barrier. ${ }^{34}$

The rotational behaviour of rats appears to arise from unilateral activation of the striatum which induces contraversive rotations. ${ }^{38}$ This area was regularly affected in our animals (fig 4). Hypoxia is shown to impede both the oxygen-dependent rate limiting steps of neurotransmitter synthesis and those of inactivation..$^{39-42}$ The storage mechanisms of synaptic vesicles, the maintenance of membrane potentials and the re-uptake by presynpatic neuron of origin are also dependent on the presence of energy rich phosphates. ${ }^{40}$ Low intensity hypoxia increases neurotransmitter concentration within the synaptic cleft inducing an activation of the system involved.: During the course of severe hypoxiaischaemia a gradual loss of catecholamines is known 
to occur. This is caused in part by tissue necrosis leading to transmitter leakage via degradation of membrane integrity, ${ }^{3942}$ in part by the impeded influx of precursors. ${ }^{3940}$

During the initial phase of carbon monoxide exposure there is a predominant "activation" of the ipsilateral hemisphere caused by hypoxia-induced transmitter release. After the 35th minute of the exposure the contralateral hemisphere preponderates reflecting energy exhaustion and depletion of neurotransmitters in the ipsilateral hemisphere.

The intensity of the brain damage revealed histologically corresponds well with the course of the number of rotating animals (fig 7). In the slightly affected rats the ipsilateral hemisphere predominates during the whole carbon monoxide exposure, whereas in the more severely damaged animals the contralateral hemisphere predominates from the 25 th minute onwards. Thus, in the surviving animals the neuropathological outcome can be predicted in statistical terms from the 30th minute of the exposure onwards. Survival, however, cannot be predicted until the recovery phase. In contrast to what is observed in the survivors, the number of rotating animals increases in the nonsurvivorspredominantly the frequency of the contraversive ones (fig 7). They display, in addition, an ictal quality with increased velocity of rotating confirming observations in the Levine model. ${ }^{43}$ Often rotation is combined with running and jumping fits which are well known to be included by anoxic-ischaemic brain lesions.

The pathophysiological data did not allow prediction of survival, until the recovery phase which shows a significantly delayed restoration of the all important ipsilateral EEG. Although not apparently significant, it is noteworthy that there was complete flattening of the ipsilateral EEG during the last 20 minutes of the exposure in all of the nonsurvivors, whereas in most of the survivors there was some resting activity of low frequency and amplitude (fig 10). Since electric silence persisted until the 15 th minute of the recovery period (probably due to the slowness of the $\mathrm{CO}-\mathrm{Hb}$ desaturation), its whole duration amounted to 35 minutes. This agrees with findings in monkeys which show that the duration of EEG flattening critical for the development of marked ischaemic infarcts is 25 minutes. ${ }^{28}$

The marked respiratory depression and steeper increase of systemic arterial pressure in the nonsurvivors, concomitant with a slight decrease of the heart rate (fig 10), can probably be attributed to a primary cerebral ischaemic response arising from compression of the medullary centres ${ }^{445}$ with increasing brain swelling.

In addition to reducing the oxygen transport capacity of haemoglobin the carbon monoxide molecule can inhibit cellular metabolism by liganding the iron haematin radicles of cytochrome oxidases. ${ }^{46}$ There is evidence that in intact animals of different species lesions of the central nervous system may occur after exposure to carbon monoxide concentrations of the magnitude used in this study. These lesions are focal interstitial and/or cellular oedema,${ }^{47}$ myelinolysis ${ }^{204849}$ and peripheral nerve lesions..$^{5051}$ However, in none of these studies were the circulatory effects of carbon monoxide eliminated in order to isolate its cellular effects. Moreover, extensive necrosis of the white matter (probably of axonal origin ${ }^{52}$ ) induced in anaesthetised dogs, ${ }^{20}$ cats $^{5253}$ and monkeys ${ }^{48}$ by single carbon monoxide exposures could be ascribed to circulatory and respiratory sequelae of functional anaemia. ${ }^{48} 53$ Similar lesions have been observed in man following carbon monoxide exposure and numerous other conditions, the common denominator of which has appeared to be hypotension and severe acidosis. ${ }^{54}$

Apparently there are considerable species and strain differences in the susceptibility to these mechanisms. Like others ${ }^{55}$ we have never seen brain lesions occur after carbon monoxide exposure in intact rats.

Finally we wish to stress that we have found considerable strain differences in the results of carbon monoxide exposure and unilateral common carotid artery ligation. Most probably these can be attributed to differences in cephalic collateral blood supply. ${ }^{56}$

The authors are indebted to Mrs A Jakob for skilful technical assistance.

\section{References}

${ }^{1}$ Levine S, Payan H. Effects of ischemia and other procedures on the brain and retina of the gerbil (Meriones unguiculatus). Exp Neurol 1966;16:255-62.

${ }^{2}$ Levine S. Anoxic-ischemic encephalopathy in rats. Am J Pathol 1960;36:1-17.

${ }^{3}$ Clendenon NR, Allen N, Komatsu T, Liss L, Gordon WA, Heimberger $K$. Biochemical alterations in the anoxic-ischemic lesion of rat brain. Arch Neurol 1971;25:432-48.

${ }^{4}$ Spataro J. Anoxic-ischemic encephalopathy of the rat brain. Exp Neurol 1966;16:16-27.

${ }^{5}$ Salford LG, Plum F, Siesjö BK. Graded hypoxia oligemia in rat brain $\mathrm{I}$. Biochemical alterations and their implications. Arch Neurol 1973;29:227-33.

${ }^{6}$ Holland $\mathrm{RAB}$. Rate of $\mathrm{O} 2$ dissociation from $\mathrm{O} 2 \mathrm{Hb}$ and relative combination rate of $\mathrm{CO}$ and $\mathrm{O} 2$ in mammals at $37^{\circ}$ C. Respir Physiol 1969;7:30-42.

${ }^{7}$ Shepherd JT, Pelletier CL. Carotid chemoreflex and circulatory control. In: Purves MJ, ed. The Peripheral Arterial Chemoreceptors. Cambridge University Press, 1975;463-75. 
${ }^{8}$ Duke HN, Green JH, Neil E. Carotid chemoreceptor impulse activity during inhalation of carbon monoxide mixtures. J Physiol (Lond) 1952;118:520-7.

${ }^{9}$ Chiodi H, Dill DB, Consolazio F, Horvath SM. Respiratory and circulatory responses to acute carbon monoxide poisoning. Am J Physiol 1941;134:683-93.

${ }^{10}$ Daly M deB, Scott MJ. The cardiovascular responses to stimulation of the carotid body chemoreceptors in the dog. J Physiol (Lond) 1963;165:179-97.

"Kontos HA, Vetrovec GW, Richardson DW. Role of carotid chemoreceptors in circulatory response to hypoxia in dogs. J Appl Physiol 1970;28:561-5.

${ }^{12}$ Sylvester JT, Scharf SM, Gilbert RD, Fitzgerald RS, Traystman RJ. Hypoxic and CO hypoxia in dogs: hemodynamics, carotid reflexes and catecholamines. Am J Physiol 1979;236:H22-H28.

${ }^{13}$ Marotta SF. Roles of aortic and carotid chemoreceptors in activating the hypothalamo-hypophysealadrenocortical system during hypoxia (36901). Proc Soc Exp Biol Med 1972;141:911-5.

${ }^{14}$ Fukuda T, Kobayashi T. On the relation of chemoreceptor stimulation to epinephrine secretion in anoxemia. Jpn J Physiol 1961;11:467-75.

15 Korner PI, Chalmers JP, White SW. Some mechanisms of reflex control of the circulation by the sympathoadrenal system. Circulat Res Suppl III, Vols 20 and $21 ; 1967 ; 157-72$.

${ }^{16}$ Petajan JH, Packham StC, Frens DB, Dinger BG. Sequelae of carbon monoxide induced hypoxia in the rat. Arch Neurol 1976;33:152-7.

${ }^{17}$ Miller AT Jr, Wood JJ. Effects of acute carbon monoxide exposure on energy metabolism of rat brain and liver. Environ Res 1974;8:107-11.

${ }^{18}$ Mordelet-Dambrine M, Stupfel M, Duriez M. Comparison of tracheal pressure and circulatory modifications induced in guinea pigs and in rats by carbon monoxide inhalation. Comp Biochem Physiol 1978;59A:65-8.

${ }^{19}$ Norman JN, Douglas TA, Smith G. Respiratory and metabolic changes during carbon monoxide poisoning. J Appl Physiol 1966;21:848-52.

${ }^{20}$ Preziosi TJ, Lindenberg R, Levy D, Christenson M. An experimental investigation in animals of functional and morphologic effects of single and repeated exposures to high and low concentrations of carbon monoxide. Ann NY Acad Sci 1970;174:369-84.

${ }^{21}$ Ginsberg MD, Myers RE. Experimental carbon monoxide encephalopathy in the primate. I. Physiologic and metabolic aspects. Arch Neurol 1974;30:202-8.

${ }^{22}$ Smith ID, Simmonds WJ. The changes in cardiac output, right atrial pressure and blood volume in haemorrhagic anaemias in unanesthetized rabbits. Aust $J$ Exp Biol Med Sci 1954;32:241-52.

${ }^{23}$ Myers RE, Kopf GS, Mirvis DM. Hemodynamic response to profound hypoxia in intact rhesus mi monkeys. Stroke 1980;11:622-8.

${ }^{24}$ Adams JD, Erickson HH, Stone HL. Myocardial metabolism during exposure to carbon monoxide in the conscious dog. J Appl Physiol 1973;34:238-42.

${ }^{25}$ McGrath JJ, Martin LG. Effects of carbon monoxide on isolated heart muscle (40121). Proc Soc Exp Biol Med 1978;157:681-3.

${ }^{26}$ Scharf SM, Permutt S, Bromberger-Barnea B. Effects of hypoxic and CO hypoxia on isolated hearts. $J$ Appl Physiol 1975;39:752-8.

${ }^{27}$ Graham DI, Fitch W, MacKenzie ET, Harper AM. Effects of hemorrhagic hypotension on the cerebral circulation. III. Neuropathology Stroke 1979;10:724-7.

${ }^{28}$ Selkoe DJ, Myers RE. Neurologic and cardiovascular effects of hypotension on the monkey. Stroke 1979;10:147-57.

${ }^{29}$ Gregory PC, McGeorge AP, Fitch W, Graham DI, MacKenzie ET, Harper AM. Effects of hemorrhagic hypotension on the cerebral circulation. II. Electrocortical function. Stroke 1979;10:719-23.

${ }^{30}$ Laas R, Arnold H. Brain infarction in the mongolian gerbil. Correlations between common carotid artery stump pressure, neurological symptoms, and morphological findings. Acta Neurol Scand Suppl 1979;72 (60):340-1.

${ }^{31}$ Brown AW, Brierley JB. The nature, distribution and earliest stages of anoxic-ischaemic nerve cell damage in the rat brain as defined by the optical microscope. Br J Exp Pathol 1968;49:87-106.

${ }^{32}$ Salford LG, Plum F, Brierley JB. Graded hypoxiaoligemia in rat brain. II. Neuropathological alterations and their implications. Arch Neurol 1973;29:234-8.

${ }^{33}$ Little JR, Kerr FWL, Sundt TM. Microcirculatory obstruction in focal cerebral ischemia: an electron microscopic investigation in monkeys. Stroke 1976;7:25-30.

${ }^{34}$ Fujimoto T, Walker JT Jr, Spatz M, Klatzo I. Pathophysiologic aspects of ischemic edema. In: Pappius HM, Feindel W, eds. Dynamics of Brain Edema. New York: Springer, 1976;17.1-180.

${ }^{35}$ Olsson Y, Crowell RM, Klatzo I. The blood-brain barrier to protein tracers in focal cerebral ischemia and infarction caused by occlusion of the middle cerebral artery. Acta Neuropath (Berl) 1971;18:89-102.

${ }^{36}$ Hayakawa T, Waltz AG, Jacobson RL. Hypertension and acute focal cerebral ischemia. Stroke 1979;10:263-7.

${ }^{37}$ Petito CP. Platelet thrombi in experimental cerebral infarction. Stroke 1979;10:192-6.

${ }^{38}$ Ungerstedt U. Striatal dopamine release after amphetamine or nerve degeneration revealed by rotational behaviour. Acta Physiol Scand 1971;Suppl 367:49-68.

${ }^{39}$ Mrsulja BB, Mrsulja BJ, Spatz M, Ito U, Walker JT, Klatzo I. Experimental cerebral ischemia in mongolian gerbils. IV. Behaviour of biogenic amines. Acta Neuropath (Berl) 1976;36:1-8.

${ }^{40}$ Brown RM, Carlson A, Ljunggren B, Siesjö BK, Snider SR. Effect of ischemia on monoamine metabolism in the brain. Acta Physiol Scand 1974;90:789-91.

${ }^{41}$ Davis JN, Carlsson A. The effect of hypoxia on monoamine synthesis, levels and metabolism in rat brain. $J$ Neurochem 1973;21:783-90.

${ }^{42}$ Lust WD, Mrsulja BB, Mrsulja BJ, Passonneau JV, Klatzo I. Putative neurotransmitters and cyclic nucleotides in prolonged ischemia of the cerebral cortex. Brain Res 1975;98:394-9.

${ }^{43}$ Kuwashima J, Fujitani B, Nakamura K, Kadokawa T, Yoshida K, Shimizu M. Biochemical changes in 
unilateral brain injury in the rat: a possible role of free fatty acid accumulation Brain Res 1976;110:547-57.

${ }^{44}$ Dampney RAL, Kumada M, Reis DJ. Central neural mechanisms of the cerebral ischemic response. Circ Res 1979;45:48-62.

${ }^{45}$ Kumada M, Dampney RAL, Reis DJ. Profound hypotension and abolition of the vasomotor component of the cerebral ischemic response produced by restricted lesions of medulla oblongata in rabbit. Circulation Res 1979;45:63-70.

${ }^{46}$ Chance B, Erecinsky M, Wagner M. Mitochondrial responses to carbon monoxide toxicity. Ann NY Acad Sci 1970;174:193-204.

${ }^{47}$ Chan-Palay V, McGroskey L. The effects of carbon monoxide on neurons of the cerebellum. Neuropath Appl Neurobiol 1976;2:293-312.

${ }^{48}$ Ginsberg MD, Myers RE. Experimental carbon monoxide encephalopathy in the primate. II. Clinical aspects, neuropathology, and physiologic correlation. Arch Neurol 1974;30:209-16.

${ }^{49}$ Takeichi M. Electron microscopic observation on occipital lobes of experimentally incuced $\mathrm{CO}$ poisoning in cats. J Electron Microscopy 1968;17:87.
${ }^{50}$ Grunnet ML, Petajan JH. Carbon monoxide-induced neuropathy in the rat. Arch Neurol 1976;33:158-63.

51 Snyder RD. Carbon monoxide intoxication with peripheral neuropathy. Neurology (Minneap) 1970;20:177-80.

52 Horita N, Ando S, Seino S, Hagiwara I. Experimental carbon monoxide leucoencephalopathy in the cat. $J$ Neuropath Exp Neurol 1980;39:197-211.

${ }^{53}$ Okeda R, Funata N, Takano T, Miyazaki Y, Higashino F, Yokoyama K, Manabe M. The pathogenesis of carbon monoxide encephalopathy in the acute phasephysiological and morphological correlation. Acta Neuropathol (Berl) 1981;54:1-10.

${ }^{54}$ Ginsberg MD, Hedley-Whyte ET, Richardson EP. Hypoxic-ischemic leucoencephalopathy in man. Arch Neurol 1976;33:5-14.

55 Mawatari S. Biochemical study on rat brain in acute carbon monoxide poisoning. Fol Psychiat Neurol Jap 1970;24:123-9.

${ }^{56}$ Payan HM, Levine S, Strebel R. Effects of cerebral ischemia in various strains of rats. Proc Soc Exp Biol Med 1965;120:208-9. 